\title{
Effect of organic fertilization on quality and yield of oriental tobacco (Nicotiana tabacum L.) under Mediterranean conditions
}

\author{
Ioanna Tabaxi ${ }^{1}$, Charikleia Zisi' ${ }^{1}$, Stella Karydogianni1 ${ }^{1}$, Antigoni-Eleni Folina', Ioanna Kakabouki ${ }^{1}$, Apostolos \\ Kalivas $^{2}$, Dimitrios Bilalis ${ }^{1}$ \\ ${ }^{1}$ Department of Crop Science, Agricultural University of Athens, Greece \\ ${ }^{2}$ Plant Breeding and Genetic Resources Institute, Hellenic Agricultural Organization, DEMETER, Thermi, Greece
}

\begin{abstract}
Received:
May 07, 2020

Accepted:

June 26, 2020

Online First:

October 17, 2020

Published:

January 30, 2021

Abstract

Greece is a country that primarily cultivates tobacco. Over the years and the increase of inputs to conventional tobacco cultivation and the groundwater nitrate pollution, producers and industry began to look at organic farming. However, for the field crop of tobacco knowledge is limited to inorganic fertilization only and it is necessary now to find out the effect of organic fertilization on soil, yield and quality of tobacco. Therefore, two-year field experiments were carried out during 2017-2018 in Agricultural University of Athens. Three oriental tobacco varieties were cultivated (Basmas Xanthi 81, Katerini S53 and Myrodata Agriniou 30A) in split-plot design, with four fertilization treatments (Control, Compost, Manure and NPK). According to the results, the yield was significantly affected only by the variety and the highest yield was 3.488 (kg ha-1) in Myrodata Agriniou variety. The plant height was significantly affected by variety and ranged from $110,77 \mathrm{~cm}$ (Basmas Xanthi) to $121.42 \mathrm{~cm}$ (Myrodata Agriniou). The number of leaves was significantly affected only by the variety; Katerini S53 had the highest number. The nicotine content was significantly affected by variety and year and ranged between 2.52\% (Myrodata Agriniou) and 4.22 $\%$ (Basmas Xanthi). As nicotine increases, sugars finally decrease with the application of organic fertilizers. Summarizing, most of the soil characteristics significantly affected by the fertilization and showed generally improvement. The plant growth and the final yield was determined by the variety. With organic tobacco cultivation, the quality and yields of oriental varieties have improved significantly.
\end{abstract}

(nending author email:

bilalisdimitrios@gmail.com

Keywords: Nicotine content, Organic fertilization, Oriental tobacco, Yield

How to cite this:

Tabaxi I, Zisi Ch, Karydogianni S, Folina AE, Kakabouki I, Kalivas A and Bilalis D, 2021. Effect of organic fertilization on quality and yield of oriental tobacco (Nicotiana tabacum L.) under Mediterranean conditions. Asian J. Agric. Biol. 2021(1). DOI: https://doi.org/10.35495/ajab.2020.05.274

This is an Open Access article distributed under the terms of the Creative Commons Attribution 3.0 License. (https://creativecommons.org/licenses/by/3.0), which permits unrestricted use, distribution, and reproduction in any medium, provided the original work is properly cited.

\section{Introduction}

Tobacco is a widespread crop of great economic importance in large cultivated areas. Chemical composition of tobacco leaves is used by industry for a recreational reason, by medicine for medical uses and for biofuel production (Song et al., 2016). For Greece, tobacco is a crop that brings in a lot of income 
to farmers and organic tobacco is a new industrial product (Bilalis et al., 2009). Despite the great variability of soil and climatic conditions, time selection for leaf harvest, which is defined by mature period, is important for yield and quality of tobacco leaves (Song et al., 2016). On the other hand, nutrient management is very important in tobacco production, as it affects yield and quality to a greater extent (Prince et al., 2015). Nitrogen application of fertilizer increases the number of leaves per plant, size of leaves and therefore yield of 'flue-cured' tobacco (Smith, 2009). Flower (1999) reported even the excessive application of inorganic fertilizers with nitrogen, tobacco will take advantage of them and increase its yield. Excess nitrogen can also give off spicy aromas but does not necessarily increase nicotine (Hoyos et al., 2015).

The yield, quality and usability of tobacco depend on three important factors: the genetic potential of a variety, the environmental conditions of production and the specific cultivation practices applied to each crop (Bilalis et al., 2010). All the experiments that have been done so far show that each factor contributes to the efficiency of production and it is difficult to distinguish who is more important. The genetic potential of each tobacco variety theoretically exceeds some limits in the appearance of a particular trait.

The demand for organic tobacco is "gaining" more and more ground. There is a growing interest in the cultivation of organic tobacco worldwide, since, in addition to being the final product of conventional tobacco, in terms of concentration of toxic and hazardous substances, it also has advantages such as increasing soil fertility, minimizing producers' exposure to toxic chemicals. Increase in biodiversity, reduction of groundwater and river pollution, reduction of production costs (fewer inputs) and finally increased selling price of the product. The quantities nitrogen applied vary, indicating that they range from 56 (Smith, 2009) to $181 \mathrm{~kg}$ ha-1 (Hoyos et al., 2015). Nitrogen is an important element in tobacco fertilization as the concentration of nitrogen in leaves is highly correlated with nicotine (Bilalis et al., 2010; Bilalis et al., 2015; Richmond et al, 2016). But, tobacco is a widely cultivated crop, so the environmental impact of adding inorganic fertilizers is enormous.

Organic fertilizers enrich soil without disturbing its biological, chemical and physical properties (Bilalis and Karamanos, 2010). Organic tobacco cultivation is not widespread, although other crops have found results equal to conventional agriculture. Other results show that the quality characteristics of tobacco improved in organic fertilization.

Jianhua et al., (2006) noted that comparison between the effect of organic manure and inorganic fertilizer with the same amounts of nutrients showed that, under manure fertilization, the ratio of excellent tobacco leaves to total leaves increased. In addition, a combination of inorganic and organic fertilizer in tobacco cultivation improves the quality of tobacco. In particular, it increases the ratio of phosphorus and potassium distribution in leaves and nitrogen in roots and decreased in stems. Also with the increase of cow manure and rapeseed cake nitrogen content in leaves increased. Also, a combination of organic and inorganic fertilizers accelerated accumulation of dry matter of cured tobacco, especially in the later period of growth.

Furthermore, quality characteristics of tobacco such as aromatic substances are affected by the organic carbon content of organic matter (Yan et al., 2020; Zhang et al., 2020). Because tobacco is a large-scale crop, organic tobacco cultivation can continue to be grown on a large scale. This is very important as controversy over organic tobacco cultivation always arises with the argument that it will not be able to reach yields of conventional agriculture. It was reported that with addition of $25 \%$ chicken manure to nicotine, total sugar, total nitrogen and potassium content in leaves were at the maximum levels of flue-cured tobacco. An important element that affects the quality characteristics of tobacco, like nicotine, is variety. Also, chlorine content in irrigation water can significantly affect tobacco quality (Tabaxi et al., 2020).

Given the importance of soil fertility and the development of appropriate nutritional strategies for organic tobacco growing, the aim of this study was to study the effect of soil characteristics on the quality characteristics of tobacco and to determine the quality characteristics of tobacco during two growing cycles under different fertilizer sources with an emphasis on exploring the possible replacement of cultivation systems and fertilization strategies applied so far.

\section{Material and Methods}

\section{Experimental design}

Two tobacco (Nicotiana tabacum L.) experiments, were carried out in the experimental field of the Agricultural University of Athens, during the years 2017-2018. The soil was clay loam (CL), pH:7.29, 


\section{Tabaxi Ioanna et al.}

NO3-N, P and K, at $12.4 \mathrm{mg} \mathrm{kg-1,13.2} \mathrm{mg} \mathrm{kg-1} \mathrm{soil}$ and $201 \mathrm{mg} \mathrm{kg}-1$ soil, respectively. In addition, the percentage of $\mathrm{CaCO} 3$ was $15.99 \%$ and organic matter content was 1.47\% (Garg and Bahl, 2008). Three different oriental tobaccos' varieties (Basmas Xanthi 81, Katerini S53 and Myrodata Agriniou 30A) were cultivated. In addition to tobacco, which was the main crop, vetch (Vicia sativa) was cultivated as green manure at the experimental field. The experiments were held on an area of $600 \mathrm{~m} 2$, according to spilt plot design, with three blocks, four main plots (fertilization treatments) and 48 sub-plots (tobacco varieties). Fertilizer treatments included control (without fertilizer), inorganic fertilizer Fertiblue $12 \mathrm{~N}$ - 12P2O5$17 \mathrm{~K} 2 \mathrm{O}-2 \mathrm{MgO}+(800 \mathrm{~kg}$ ha-1), cattle manure, from Agricultural University of Athens (2100 kg ha-1), and the organic compost SUPER ECO-VAS $6 \mathrm{~N}-8$ P2O5$10 \mathrm{~K} 2 \mathrm{O}+3.3+0.3 \mathrm{~B}+1 \% \mathrm{ZnSO} 4$ by livestock products (1500 kg ha-1). Tobacco seedlings were cultivated in float system with organic fertilization (Fishfert), as well as the organic enhancer Trianum $\mathrm{P}$ for plant protection.

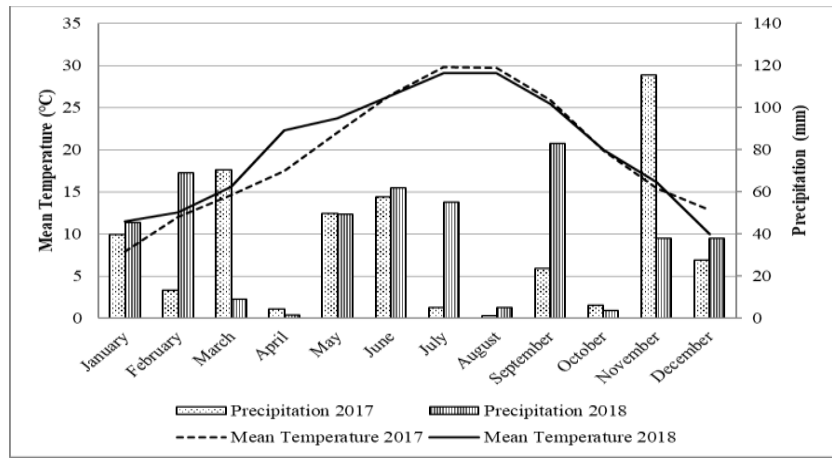

Figure-1. Annually climate data, mean temperature and precipitation during the years 2017-2018.

The field was prepared with the same tillage system (plough tillage and following from rotary hoeing), in both years. The seedlings were transplanted on April 24, 2017, and on April 19, 2018. The seedlings were transplanted by hand at a density of $50 \mathrm{~cm}$ between rows and $40 \mathrm{~cm}$ between plants in the same row. Each plot was consisted of eight rows. The observations were made from specific samples of the midline of each plot. Irrigation was done with a drip system. A total of 12 irrigations were carried out during each growing season, with $3 \mathrm{~m} 3$ per irrigation. Weed control was done by hand. The climate data, mean temperature and precipitation, during both years are presented to the Figure 1.

\section{Measurements}

Soil parameters were measured at the end of the growing season. The determination of organic matter content was carried out by the method of WalkleyBlack. In addition, the calcium carbonate $(\%)(\mathrm{CaCO} 3)$ was calculated using the Bernard device. The soil total nitrogen (mg g-1), as well as the tissue nitrogen content, was determined using the Kjeldahl method (Bremner, 1960). Moreover, phosphorus (ppm g-1) (P), was measured by the Olsen (Olsen and Watanabe, 1957) method. Total plant height $(\mathrm{cm})$, the number of leaves per plant, leaf area ( $\mathrm{cm} 2)$ and yield (kg ha-1) were determined. The leaf area was calculated using equation 1 (Moustakas and Ntzanis, 1998).

$S=k(L \times W) \quad$ eq. 1

$\mathrm{S}=$ leaf area,

$\mathrm{L}=$ leaf length,

$\mathrm{W}=$ leaf width and

$\mathrm{k}$ is an empirical constant obtained by linear regression of a sample of measurement values of $\mathrm{L}, \mathrm{W}$ and $\mathrm{S}$.

Nicotine content $(\%)$ and sugars $(\%)$ of leaves were determined by CORESTA methods, no. 35 (ISO/DIS15152) and no. 38 (ISO/DIS 15154).

\section{Statistical analysis}

Analysis of variance was carried out on data using the Statistica logistic package as a spilt-plot design. The significance of differences between treatments was estimated using Tukey's test and probabilities equal to or less than 0.05 considered significant.

\section{Results}

Table 1 provides soil characteristics that were affected by fertilization treatments. As a result of statistical analysis, variety had no significant effects on organic matter, $\mathrm{CaCO} 3$ or soil nitrogen. On treatments of manure organic matter content was significantly higher than in other treatments. Between two years, in oriental tobacco cultivation, the percentage of organic matter significantly increased on all treatments by $4 \%$ on average. $\mathrm{CaCO} 3$ and total $\mathrm{N}$ on soil were significantly affected by fertilizer. As expected NPK treatments showed the greatest values of $\mathrm{CaCO} 3$ and $\mathrm{N}$ on both years. Differences between two cultivation periods 2017 and 2018 were not reported although a slight increase of $\mathrm{N}$ soil on the second year was shown. 
Table-1. Effects of fertilization on soil characteristics.

\begin{tabular}{|c|c|c|c|c|c|c|c|}
\hline \multirow{5}{*}{$\widehat{\bar{\theta}}$} & \multirow[b]{2}{*}{ control } & \multicolumn{2}{|c|}{$\begin{array}{c}\text { organic } \\
\text { matter }\end{array}$} & \multicolumn{2}{|c|}{$\mathrm{CaCO3}$} & \multicolumn{2}{|c|}{$\mathbf{N}$} \\
\hline & & 3,077 & a & 29,378 & a & 1,627 & $\mathrm{a}$ \\
\hline & compost & 3,129 & $\mathrm{a}$ & 30,667 & $\mathrm{~b}$ & 1,724 & $\mathrm{a}$ \\
\hline & manure & 3,467 & b & 29,111 & ac & 1,778 & $\mathrm{ab}$ \\
\hline & NPK & 3,016 & $\mathrm{a}$ & 32,633 & d & 1,921 & $\mathrm{bc}$ \\
\hline & $F_{\text {fert }}$ & \multicolumn{2}{|c|}{$4,775^{*}$} & \multicolumn{2}{|c|}{$28,128 * * *$} & \multicolumn{2}{|c|}{$6,314 * *$} \\
\hline \multirow{6}{*}{$\stackrel{\infty}{\stackrel{\sim}{*}}$} & control & 3,209 & $\mathrm{ab}$ & 29,528 & $\mathrm{a}$ & 1,682 & $\mathrm{~ns}$ \\
\hline & compost & 3,446 & $\mathrm{~b}$ & 30,668 & $\mathrm{~b}$ & 1,903 & $\mathrm{~ns}$ \\
\hline & manure & 3,556 & $\mathrm{~b}$ & 29,178 & $\mathrm{ac}$ & 1,773 & $\mathrm{~ns}$ \\
\hline & NPK & 2,991 & $\mathrm{a}$ & 33,184 & $\mathrm{~d}$ & 1,919 & $\mathrm{~ns}$ \\
\hline & $\mathrm{F}_{\text {Fert }}$ & \multicolumn{2}{|c|}{$4,827 * *$} & \multicolumn{2}{|c|}{$47,526 * * *$} & \multicolumn{2}{|c|}{$0,735^{n s}$} \\
\hline & $\mathrm{F}_{\text {Year }}$ & \multicolumn{2}{|c|}{$8,763 * * *$} & $0,379^{n s}$ & & \multicolumn{2}{|c|}{$0,380^{n s}$} \\
\hline
\end{tabular}

F-test ratios are from ANOVA. The letters within the columns indicate the significant differences according to Tukey's test $(\alpha=0.05)$. Significance levels: $* p<$ $0.05 ; * * \mathrm{p}<0.01 ; * * * \mathrm{p}<0.001 ; \mathrm{ns}$, not significant $(\mathrm{p}$ $>0.05)$.

Concerning morphological characteristics, only the factor of variety showed statistically significant differences (Table 2). Plant height of Katerini S53 plants was significantly higher than the other two varieties on first-year whereas in the second year in Myrodata Agriniou and Katerini S53 were reported the highest plants. Furthermore, plant height on the second year was significantly higher on Basmas Xanthi and Myrodata Agriniou than the first year ( $\mathrm{F}=$ $5,928, p=0,03$. The number of leaves of Katerini S53 reported being constantly the highest on both years whereas Myrodata Agriniou had the lowest number of leaves. Moreover, leaf area was significantly affected only by variety. The leaf area ranged from $446,8 \mathrm{~cm} 2$ (Basmas Xanthi) to 670, $3 \mathrm{~cm} 2$ (Myrodata Agriniou) on the first year. Similar results were reported in the second year with a slight increase of leaf area on Basmas Xanthi.

There were negligible effects on yields of different fertilizers though high yields on manure and compost worth noting. While there were no statistically significant differences on yields among fertilization treatments manure $(2.975 \mathrm{~kg} / \mathrm{ha}$ on average for both years) and compost (3.064 kg/ha on average for both years) treatments not only were similar to NPK conventional fertilizer $(2.794 \mathrm{~kg} / \mathrm{ha}$ on average for both years) but even exceed it on both years. Depending on the effects of variety on yields Myrodata Agriniou had the greatest yield on both years followed by Katerini S53 and Basmas Xanthi showed the lowest yields (Table 2).

Concerning the quality characteristics, nicotine was significantly affected by variety and year. There were no statistically significant differences among fertilization treatments (Table 2) during both years in all varieties. Basmas Xanthi had statistically significant higher nicotine content by Myrodata Agriniou and Katerini S53 on both years. Basmas Xanthi and Katerini S53 showed a significant decrease in nicotine content on the second year by $20 \%$ approximately.

Table-2. Effect of variety on yields, morphological and quality traits of tobacco plants.

\begin{tabular}{|c|c|c|c|c|c|c|c|c|c|c|c|c|c|}
\hline & & \multicolumn{2}{|c|}{$\begin{array}{c}\text { yields } \\
\text { (kg/ha) }\end{array}$} & \multicolumn{2}{|c|}{ height (cm) } & \multicolumn{2}{|c|}{ leaf number } & \multicolumn{2}{|c|}{ leaf area $\left(\mathrm{cm}^{2}\right)$} & \multicolumn{2}{|c|}{ nicotine $(\%)$} & \multicolumn{2}{|c|}{ sugars $(\%)$} \\
\hline \multirow{4}{*}{ 동 } & Basmas Xanthis & 2043,0 & $\mathrm{a}$ & 110,771 & a & 26,708 & $\mathrm{a}$ & 446,833 & $\mathrm{a}$ & 4,223 & $\mathrm{a}$ & 3,172 & $\mathrm{a}$ \\
\hline & Katerini S53 & 3058,27 & $\mathrm{~b}$ & 119,979 & $\mathrm{~b}$ & 27,75 & $\mathrm{a}$ & 600,167 & $\mathrm{~b}$ & 3,674 & $\mathrm{~b}$ & 2,485 & $\mathrm{~b}$ \\
\hline & Myrodata Agr. & 3202,87 & $\mathrm{~b}$ & 112,792 & a & 20,958 & $\mathrm{~b}$ & 670,333 & $\mathrm{~b}$ & 2,527 & $\mathrm{c}$ & 2,382 & $\mathrm{~b}$ \\
\hline & $\mathrm{F}_{\text {Var }}$ & \multicolumn{2}{|c|}{$12,539 * * *$} & \multicolumn{2}{|c|}{$9,054 * *$} & \multicolumn{2}{|c|}{$28,228 * * *$} & \multicolumn{2}{|c|}{$5,733 * *$} & \multicolumn{2}{|c|}{$21,744 * * *$} & \multicolumn{2}{|c|}{$23,128 * * *$} \\
\hline \multirow{5}{*}{$\stackrel{\infty}{\tilde{\nabla}}$} & Basmas Xanthis & 2022,79 & $\mathrm{a}$ & 115,417 & $\mathrm{a}$ & 22,917 & $\mathrm{a}$ & 474,506 & $\mathrm{a}$ & 3,341 & $\mathrm{a}$ & 3,813 & $\mathrm{a}$ \\
\hline & Katerini S53 & 3260,48 & b & 120,167 & $\mathrm{~b}$ & 26,917 & $\mathrm{~b}$ & 591,414 & $\mathrm{ab}$ & 2,63 & $\mathrm{~b}$ & 2,701 & $\mathrm{~b}$ \\
\hline & Myrodata Agr. & 3488,39 & D & 121,417 & $\mathrm{~b}$ & 22,167 & $\mathrm{a}$ & 657,761 & $\mathrm{~b}$ & 2,335 & $\mathrm{~b}$ & 3,373 & $a b$ \\
\hline & $\mathrm{F}_{\text {Var }}$ & \multicolumn{2}{|c|}{$8,832 * * *$} & \multicolumn{2}{|c|}{$6,876 *$} & \multicolumn{2}{|c|}{$8,803 * *$} & \multicolumn{2}{|c|}{$4,082 *$} & \multicolumn{2}{|c|}{$6,786 * *$} & \multicolumn{2}{|c|}{$20,232 *$} \\
\hline & $\mathrm{F}_{\text {Year }}$ & \multicolumn{2}{|c|}{$0,808^{n s}$} & \multicolumn{2}{|c|}{$5,928^{*}$} & \multicolumn{2}{|c|}{$3,203^{n s}$} & \multicolumn{2}{|c|}{$0,003^{n s}$} & \multicolumn{2}{|c|}{$20,251 * *$} & \multicolumn{2}{|c|}{$4,427 *$} \\
\hline
\end{tabular}

F-test ratios are from ANOVA. The letters within the columns indicate the significant differences according to Tukey's test $(\alpha=0.05)$. Significance levels: ${ }^{*} \mathrm{p}<0.05$; ** $\mathrm{p}<0.01 ; * * * \mathrm{p}<0.001$; ns, not significant $(\mathrm{p}>0.05)$. 
Tabaxi Ioanna et al.

Table-3. Correlation matrix between soil, agronomic and quality characteristics in different tobacco varieties.

\begin{tabular}{|c|c|c|c|c|c|c|c|c|}
\hline & $\begin{array}{c}\text { organic matter } \\
\%\end{array}$ & $\begin{array}{c}\mathrm{CaCO}_{3} \\
\%\end{array}$ & $\begin{array}{l}\mathrm{N} \text { soil } \\
\mathrm{mg} \mathrm{g}^{-1}\end{array}$ & $\begin{array}{c}\text { Nicotine } \\
\%\end{array}$ & $\begin{array}{c}\text { Sugars } \\
\%\end{array}$ & $\begin{array}{c}\text { Yield } \\
\text { kg.ha- }\end{array}$ & $\begin{array}{c}\text { Height } \\
\mathrm{cm}\end{array}$ & $\begin{array}{c}\text { Leaves no } \\
\text { plant }^{-1}\end{array}$ \\
\hline $\mathrm{CaCO}_{3} \%$ & $0.12^{\mathrm{ns}}$ & & & & & & & \\
\hline $\mathrm{N}$ soil $\mathrm{mg} \mathrm{g}^{-1}$ & $0.01^{\mathrm{ns}}$ & $0.28^{*}$ & & & & & & \\
\hline Nicotine $\%$ & $-0.04^{\mathrm{ns}}$ & $-0.03^{\mathrm{ns}}$ & $0.35^{\mathrm{ns}}$ & & & & & \\
\hline Sugars $\%$ & $-0.08^{\mathrm{ns}}$ & $0.20^{\mathrm{ns}}$ & $0.08^{\mathrm{ns}}$ & $-0,61 * *$ & & & & \\
\hline Yield kg ha-1 & $-0.02^{\mathrm{ns}}$ & $0.00^{\mathrm{ns}}$ & $-0.02^{\mathrm{ns}}$ & $-0.36^{* *}$ & $-0.10^{\mathrm{ns}}$ & & & \\
\hline Plant Height $\mathrm{cm}$ & 0.20 & $-0.01^{\mathrm{ns}}$ & $-0.11^{\mathrm{ns}}$ & $-0.13^{\mathrm{ns}}$ & $-0.04^{\mathrm{ns}}$ & $0.26^{*}$ & & \\
\hline Leaves No plant-1 & $0.04^{\mathrm{ns}}$ & $0.31^{* *}$ & $-0.03^{\mathrm{ns}}$ & $0.31^{* *}$ & $-0.03^{\mathrm{ns}}$ & $0.01^{\mathrm{ns}}$ & $0.19^{\text {ns }}$ & \\
\hline leaf area $\mathrm{cm}^{2}$ & $0.10^{\mathrm{ns}}$ & $0.03^{\mathrm{ns}}$ & $-0.21^{\mathrm{ns}}$ & $-0.28^{*}$ & $-0.08^{\mathrm{ns}}$ & $0.17^{\text {ns }}$ & $0.00^{\mathrm{ns}}$ & $-0.17^{\mathrm{ns}}$ \\
\hline
\end{tabular}

F-test ratios are from ANOVA. The letters within the columns indicate the significant differences according to Tukey's test $(\alpha=0.05)$. Significance levels: $* p<0.05$; ** $p<0.01$; *** $p<0.001$; ns, not significant $(\mathrm{p}>0.05)$.

The percentage of sugar was statistically significant affected mostly by year and variety. Fertilizer treatments didn't seem to affect sugar content. In comparison with nicotine, sugar content showed a significant increase on the second year and the values ranged from 3,17 \% (Basmas Xanthi) to 2,3\% (Myrodata Agriniou) for the first year and 3,81\% (Basmas Xanthi) to $2,7 \%$ (Katerini S53) for the second year.

Inverse relationship between nicotine and total sugars content was reported as expected by negative correlation $(\mathrm{r}=-0,61, \mathrm{p}=0,0043)$ as shown in Table 3 .

\section{Discussion}

With the cultivation practices applied, the soil parameters were positively affected, especially in the treatments with organic fertilizers, resulting in an increase of the organic matter. Soil quality is affected by the content of organic matter. In the present study, organic matter was affected by various fertilizer treatments. Several studies have shown that organic matter is closely related to organic fertilizers such as compost (Casado-Vela et al., 2007). Kakabouki et al., (2018) observed that manure treatment increases the organic matter of the soil. Furthermore, the application of organic fertilizers affects the composition of soil microbial community which is a result of accumulation of organic carbon in soil (Bilalis et al., 2010). According to Table 1, the $\mathrm{CaCO}_{3}$ percentage was affected by the various fertilizer treatments and especially by the inorganic fertilizer. Concerning total nitrogen on the soil it is known that can increase by organic fertilization, as it is a component of organic matter (Kakabouki et al., 2018).
According to our results, the total $\mathrm{N}$ soil content differ significantly between fertilizer treatments only the first year of the experiment but sufficient quantity of $\mathrm{N}$ on soil was reported on both years.

Song et al., (2016) reported that in different concentrations of organic fertilizers in tobacco, differences in the morphological characteristics of the plant were recorded. In our results in both years, organic fertilizers did not significantly affect morphological traits though plants in compost treatment had the greatest values on height. It was also reported that increasing the number of leaves per plant is not a significant factor in increasing yields. The number of leaves per plant was less than that recorded in the experiment of Kurt and Ayan, (2014), which is probably due to the climate conditions but also to the varieties used. The number of leaves per plant showed a positive correlation with the nicotine content $(\mathrm{r}=0.31, \mathrm{p}=0.008)$ (Table 3$)$. In the study of Kurt and Ayan, (2014) they reported that as the applied dose of organic fertilizers increased, so did the surface of the leaves. In our study, the fertilization with compost had the largest leaf area but no statistically significant differences from the other treatments.

According to Kurt and Ayan (2014), the organic fertilization applied on tobacco crop resulted in an increase in yield, emphasizing the fact that the increase in the applied dose causes a parallel increase in yield. Although fertilization did not affect the yields of tobacco crop on our experiment organic fertilization met the expectations and exceeded in yields conventional fertilizer. Soil organic matter is an important factor in determining yields in many crops. In the cultivation of tobacco, it was noted that organic matter in the soil below $2 \%$, the addition of organic 


\section{Tabaxi Ioanna et al.}

fertilizers increased yield vertically while at more than $2 \%$ it did not increase significantly (Drake et al., 2015; Jianhua et al., 2006). Regarding how variety affects yields all three varieties gave yields in between the typical range as reported on the national catalogue.

Nutrition is important for the growth and yield of tobacco, as well as for the synthesis and accumulation of nicotine (Henry et al., 2019; Vann and Fisher, 2017). Every key nutrient plays an integral role in tobacco growth, but none is as important to nicotine production as nitrogen. Nitrogen uptake occurs mainly in the early stages of development, before the top of the shoot is removed (Ju et al., 2008; Liu et al., 2020), while nicotine is synthesized mainly in later stages, in the roots of the tobacco before it is transferred to the leaves (Collins and Hawks, 1993). While Bozhiova and Bozhinov (2006) have reported that organic fertilizers, can increase nicotine content in oriental tobacco leaves, in this study organic fertilizers did not affect nicotine content. Nicotine and sugars content is mainly related to the genotype of tobacco and secondly to agronomical practices occurring to increase of nicotine content such as topping according to Damalas and Koutroubas, 2014. According to Egilmez (1988) in oriental tobacco varieties, the relationship between sugars and nicotine content is inverse. Also in this study negative correlation between these quality traits was reported $(\mathrm{r}=-0.6, \mathrm{p}=$ 0.006).

\section{Conclusion}

In conclusion, different fertilization had different effects on soil, agronomic and quality characteristics in the three oriental tobacco varieties (Basmas Xanthi, Katerini S53 and Myrodata Agriniou). Yields of tobacco crop excelled on all varieties and fertilization treatments giving us the opportunity to study more about organic tobacco in order to replace more and more conventional crops and improve soil conditions of fields on degradation.

\section{Disclaimer: None. \\ Conflict of Interest: None. Source of Funding: None.}

\section{References}

Bilalis D, Karkanis A, Efthimiadou A, Konstantas AR and Triantafyllidis V, 2009. Effects of irrigation system and green manure on yield and nicotine content of Virginia (Flue-cured) organic tobacco (Nicotiana tabacum), under Medeterranean conditions. Ind. Crops Prod. 29: 388-394.

Bilalis D, Karkanis A, Triantafyllidis V, Ladavos A, Bizos D, Patsiali S and Papatheohari Y, 2010. Effects of organic and inorganic fertilization on growth, yield and nicotine content of flue-cured and oriental tobacco (Nicotiana tabacum L.) seedlings grown in organic and conventional float system. J. Food Agric. Environ. 8(2): 585-589.

Bilalis DJ and Karamanos A, 2010. Organic maize growth and mycorrhizal root colonization response to tillage and organic fertilization. J. Sustain. Agric. 34(8): 836-849.

Bilalis DJ, Travlos IS, Portugal J, Tsioros S, Papastylianou Y, Papatheohari Y, Avgoulas C, Tabaxi I, Alexopoulouc E and Kanatas PJ, 2015. Narrow row spacing increased yield and decreased nicotine content in sun-cured tobacco (Nicotiana tabacum L.). Ind. Crops Prod. 75: 212-217.

Bozhiova P and Bozhinov V, 2006. Exploring the contents of major macro and micro elements in tobacco smoke. Sci. Works Univ. Food Technol. 51(3): 137-142.

Bremner JM, 1960. Determination of nitrogen in soil by Kjedahl method. J. Agric. Sci. 55: 11-33.

Casado-Vela J, Selles S, Diaz-Crespo M, NavarroPedreno J and Mataix-Beneyto J, 2007. Effect of composted sewage sludge application to soil on sweet pepper crop (Capsicum annuum var. annuиm) grow under tow exploitation regimes. Waste Manage. 27: 1509-18.

Collins WK and Hawks SNJr, 1993. Principles of fluecured tobacco production. North Carolina State Univ. Raleigh, NC, USA.

Damalas CA and Koutroubas SD, 2014. Determinants of farmers' decisions on pesticide use in oriental tobacco: a survey of common practices. Int. J. Pest Manage. 60: 224-231.

Drake MP, Vann MC and Fisher LR, 2015. Nitrogen Application Rate Influence on Yield, Quality, and Chemical Constituents of Flue-Cured Tobacco, Part I: Application Timing. Tobacco Sci. 52(1): 11-17. doi:10.3381/14-041R.1.

Egilmez O, 1988. Physical, Chemical, Smoke Analysis Methods for Tobacco and Cigarettes. Tekel Institute Publication. 28: 134.

Flower KC, 1999. Field Practices. In: Layton Davis and Mark Nielson. Tobacco Production, Chemistry and Technology. Blackwell, London. pp. 76-97. 


\section{Tabaxi Ioanna et al.}

Garg S and Bahl GS, 2008. Phosphorus availability to maize as influenced by organic manures and fertilizer $\mathrm{P}$ associated phosphatase activity in soils. Bioresour. Technol. 99(13): 5773-5777.

Henry JB, Vann MC and Lewis RS, 2019. Agronomic Practices Affecting Nicotine Concentration in Flue-Cured Tobacco: A Review. Agron. J. 111(6): 3067-3075.

Hoyos C, Magnitskiy S and Plaza T, 2015. Effect of fertilization on the contents of macronutrients and chlorine in tobacco leaves cv. flue-cured (Nicotiana tabacum L.) in two municipalities in Huila, Colombia. Agron. Colom. 33(2): 174-183.

Jianhua Y, Xinyao Z, Tianfu L, Wenxuan P, Shihao Y, Weiqun L and Yuhong Y, 2006. Effects of Different Cake Fertilizer Amount on Yield and Quality of Flue-cured Tobacco on Soil of Different Organic Matter Contents. Chinese Agric. Sci. Bull.10: 216-220.

Ju XT, Chao FC, Li CJ, Jiang RF, Christie P and Zhang FS, 2008. Yield and nicotine content of flue-cured tobacco as affected by soil nitrogen mineralization. Pedosphere. 18:227-235.

Kakabouki I, Hela D, Roussis I, Papastylianou P, Sestras AF and Bilalis D, 2018. Influence of fertilization and soil tillage on nitrogen uptake and utilization efficiency of quinoa crop (Chenopodium quinoa Willd.) J. Soil Sci. Plant Nutr. 18(1): 220-235.

Kurt D and Ayan AK, 2014. Effect of the Different Organic Fertilizer Sources and Doses on Yield in Organic Tobacco (Nicotiana tabacum L.) Production. J. Agric. Faculty Gaziosmanpasa Univ. 31(2):7-14. doi:10.13002/jafag593

Liu Z, Zhang F, Liu Z, Li Z, and Wang Y, 2020. Comparative analysis of aroma components of cinnabar and common tobacco leaves by HSSPME-GC/MS and their sensory differences. Tobacco Sci. Technol. 53(7): 54-61.

Moustakas NK and Ntzanis H, 1998. Estimating fluecured tobacco leaf area from linear measurements under Mediterranean conditions. Agric. Med. 128: 226-231.

Olsen SR and Watanabe FS, 1957. A method to determine a phosphorus adsorption maximum of soils as measured by the Langmuir isotherm 1. Soil Sci. Soc. Am. J. 21(2): 144-149.

Prince M, Mtaita TA and Rukuni D, 2015. Effect of leaf priming removal level and fertilization rate on yield of tobacco in Zimbabwe. Greener J. Agric. Sci. 5(1): 1-13.
Richmond MD, Pearce RC and Bailey WA, 2016. Dark Fire-Cured Tobacco Response to Potassium Rate and Application Method. Tobacco Sci. 53(1): 12-15. doi:10.3381/16-051.

Smith W, 2009. Managing nutrients. In: Flue-cured tobacco guide. North Carolina State University, Raleigh, NC, USA. pp. 58-81.

Song Z, Wang J, Sun M, Wu J, Gong C and Liu G, 2016. Effects of organic fertilizer applications on starch changes in tobacco (Nicotiana tabacum L.) leaves during maturation. Soil Sci. Plant Nutr. 62(2): 173-179. DOI: 10.1080/00380768.2016.1162110

Tabaxi I, Roussis I, Karydogianni S, Kakabouki I, Kalivas A, Folina AE and Bilalis D, 2020. Influence of chloride content in irrigation water on yield, morphological features and chemical composition of leaves of three Oriental tobacco (Nicotiana tabacum L.) cultivars. J. Elementol. 25(2): $581 \quad$ - $594 . \quad$ DOI: 10.5601/jelem.2019.24.4.1938

Vann $M$ and Fisher LR, 2017. Verification of Nitrogen and Phosphorus Application Rates To Flue-Cured Tobacco. Tobacco Sci. 54(1): 4-5.

Yan S, Niu Z, Yan H, Zhang A and Liu G, 2020. Influence of Soil Organic Carbon on the Aroma of Tobacco Leaves and the Structure of Microbial Communities. Curr. Microbiol. 77(6): 931-942.

Zhang J, Huang Y and Lin J, 2020. Biochar applied to consolidated land increased the quality of an acid surface soil and tobacco crop in Southern China. J Soils Sediment. 20, 3091-3102. https://doi.org/10.1007/s11368-019-02531-z.
Contribution of Authors
Tabaxi I: Data collection, designed research methodology and manuscript writing Zisi C, Karydogianni S, Folina AE \& Kakabouki I: Data analysis and interpretation, literature review, manuscript writing and approval Kalivas A \& Bilalis D: Designed research methodology 